Proceedings of the International School and Conference on Optics and Optical Materials, ISCOM07, Belgrade, Serbia, September 3-7, 2007

\title{
Thermoluminescent Mechanism in Lilac Spodumene
}

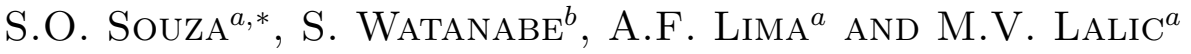 \\ ${ }^{a}$ Department of Physics, Federal University of Sergipe \\ São Cristóvão, Brazil \\ ${ }^{b}$ Department of Nuclear Physics, Institute of Physics \\ Universidade de São Paulo, São Paulo, Brazil
}

In the present work the thermoluminescence of a lilac $\alpha$-spodumene $\left(\mathrm{LiAlSi}_{2} \mathrm{O}_{6}\right)$, a natural mineral from Brazil, was investigated. Toward this aim the gamma irradiation, as well as several heating processes were carried out. The sample presented a glow curve with various thermoluminescence peaks. Emission spectrum showed only one prominent band at $610 \mathrm{~nm}$, which indicates the existence of only one recombination center despite the several thermoluminescence centers exhibited, due to intrinsic defects. Using correlation between thermoluminescence and optical absorption techniques we discuss the effects of gamma radiation and annealing in the lilac spodumene, and conclude that an annealing at about $230^{\circ} \mathrm{C}$ can be applied to natural lilac spodumene gems used in jewelry for increment of its lilac color.

PACS numbers: 91.60.- $\mathrm{x}, 78.60 . \mathrm{Kn}, 61.72 .-\mathrm{y}$

\section{Introduction}

The silicates are materials of special interest for science and technology due to their wide application in optical and semiconductor devices. $\alpha$-spodumene, $\mathrm{LiAlSi}_{2} \mathrm{O}_{6}$, is a natural mineral belonging to pyroxene group. It contains two inequivalent metal cation sites M1 and M2 occupied by Al and Li ions, respectively. Both atoms may be replaced by transition metal elements, such as $\mathrm{Mn}, \mathrm{Fe}, \mathrm{Cr}$ and others [1]. Its transparent varieties are considered as semi-precious gemstones, and besides, the natural crystals are strongly luminescent under UV or electron beam excitation [2]. These facts make the spodumene an interesting optical material for various applications in jewel industry or detector design.

The principal optical characteristics of $\alpha$-spodumene are caused by lattice defects which exist in natural samples. The most frequent are exchange of $\mathrm{Si}^{4+}$

*corresponding author; e-mail: sosouza@fisica.ufs.br 
and $\mathrm{Al}^{3+}$ ions and a presence of different impurities on substitution and interstitial sites. On exciting the samples by ionizing radiation, electrons and holes can be trapped by these sites. They can be thermally released from traps causing a radioactive recombination and thermoluminescent peaks. Thermoluminescence (TL) is a process in which heated insulator or semiconductor emits the light in correlation with the previous absorption of energy from radiation. The TL measurements performed on synthetic $\beta$-spodumene and its EPR spectra lead to the conclusion that the Fe impurity "kills" the TL centers, while the Mn impurity improves its TL response [3].

Isotani et al. [4] reported the existence of 200 and $400^{\circ} \mathrm{C}$ thermoluminescent peaks in lilac spodumene, the first correlated to the green color and the second with lilac color. Holuj [5] and Fujii and Isotani [6] studied the effects of Mn impurity in spodumene. Walker et al. [2] reported the luminescent emission spectra in various spodumene crystals. Salis [7] reported TL of colorless sample that has one TL peak at $320^{\circ} \mathrm{C}$ at $615 \mathrm{~nm}$ and a green sample that hase two TL peaks at $190^{\circ} \mathrm{C}$ and $310^{\circ} \mathrm{C}$, both at $615 \mathrm{~nm}$. The recombination centers were interpreted as holes trapped by negative charge of tetrahedral in which $\mathrm{Al}^{3+}$ ions have substituted $\mathrm{Si}^{4+}$ ions. Brovetto et al. [8] obtained $\beta$-spodumene which, after $\mathrm{X}$-irradiation, exhibited a TL peak at $277^{\circ} \mathrm{C}$ associated with two emission bands around 480 and $700 \mathrm{~nm}$.

In present work the TL and optical absorption (OA) of a natural lilac $\alpha$-spodumene from Minas Gerais State, Brazil, was investigated. Toward this aim the gamma irradiation, as well as several heating processes have been carried out. Using correlation between TL and OA techniques our main objective is to present a mechanism for effects of ionizing radiation and thermal heating in this crystal.

\section{Materials and experiments}

A large specimen of natural $\alpha$-spodumene was investigated. The lilac color of non-chromian spodumene is correlated with the presence of $\mathrm{Mn}$ and with a low $\mathrm{Fe} / \mathrm{Mn}$ ratio. The impurity content of the sample obtained in Minas Gerais State, Brazil, was analyzed with X-ray fluorescence (XRF). According to Ito and Isotani [9], the lilac color in spodumene occurs whenever the ratio of concentration $\mathrm{Mn} / \mathrm{Fe}$ is larger than 1 . In the sample investigated here this ratio is equal to 1.11 , presenting a lilac color in the $c$-axis direction and a pale yellow in the other directions.

The crystals were ground into powders and sieved to retain the grains between 0.080 to $0.180 \mathrm{~mm}$. Gamma irradiation was carried out at room temperature (RT) using a ${ }^{60} \mathrm{Co}$ source with a dose rate of $7.5 \mathrm{kGy} \mathrm{h}^{-1}$. For pre-irradiation heating process, the samples were annealed in normal air atmosphere at $600^{\circ} \mathrm{C}$ for one hour and cooled to RT suddenly.

Slabs from virgin sample of appropriated dimensions were cut perpendicular to $c$-axis and their surfaces were polished for optical absorption measurements, 
which were carried out utilizing a double beam spectrometer Cary 500 Scan (UVVis-NIR) at RT.

The glow curves were obtained from a Daybreak 1100 series automated TL reader system equipped with a photomultiplier EMI 9635B and they were recorded from RT up to $500^{\circ} \mathrm{C}$, with a heating rate of $4^{\circ} \mathrm{C} \mathrm{s}^{-1}$ in a nitrogen atmosphere. The TL spectra were recorded using a homemade TL reader equipped with an Unicom 100-FUNBEC monochromator with an accuracy of $5.0 \mathrm{~nm}$, the light being detected by a Hamamatsu 551S photomultiplier.

\section{Results and discussion}

The glow curves from natural samples with additional gamma dose are shown in Fig. 1. There are TL peaks at $170,230,340,370$, and $440^{\circ} \mathrm{C}$ (further identified as I, II, III, IV and V). As dose increases, the peak II grows faster than the others covering the peak I. The peaks III and IV do not grow much with radiation dose, being screened by the peak $\mathrm{V}$ for higher doses. All TL peaks are saturated at around 10000 Gy.

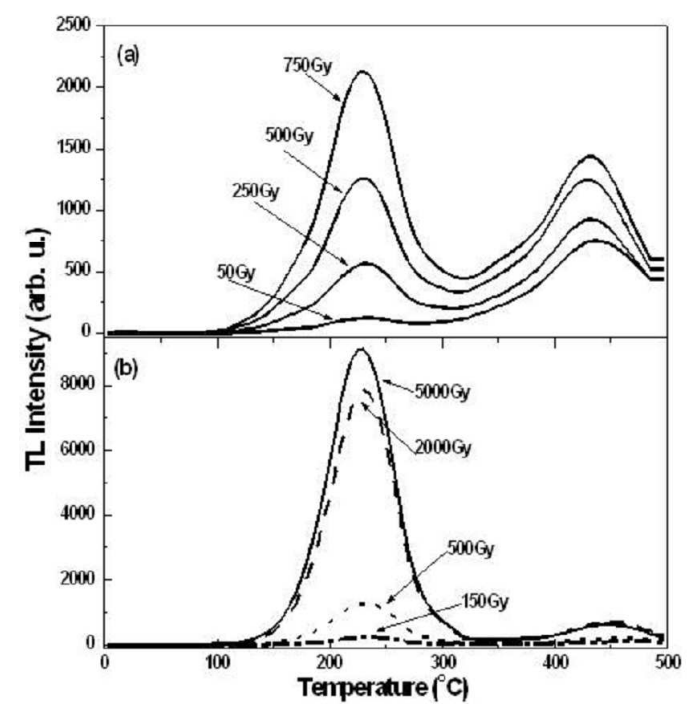

Fig. 1. Glow curves of samples irradiated with gamma dose, from 50 to 750 Gy (a) and from 150 to 5000 Gy (b).

There was chosen the most intense peak (II) to obtain the TL emission spectrum between 200 to $800 \mathrm{~nm}$, showed in Fig. 2. Around $610 \mathrm{~nm}$ a very intense band was observed, besides a very weak one around 470-480 nm. The other TL peaks showed essentially the same emission spectrum.

The higher temperature peaks (III, IV, and V) presented an unusual behavior, growing up with annealing between 150 to $200^{\circ} \mathrm{C}$. 


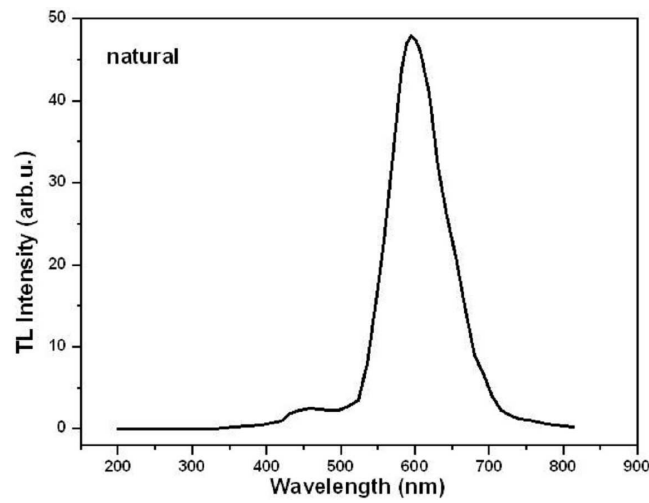

Fig. 2. TL emission spectrum of the peak II between 200 to $800 \mathrm{~nm}$.

In Fig. 3 the optical absorption spectrum is shown for the non-irradiated sample and the sample subjected to additional gamma doses. The spectrum is characterized by very weak bands around 430, 530, and $630 \mathrm{~nm}$ (the first two are correlated to original lilac color), and a very strong absorption beginning at $400 \mathrm{~nm}$. Under a heavy irradiation, the intensity of $630 \mathrm{~nm}$ band increases considerably. The $470 \mathrm{~nm}$ band, not observed before irradiation, grows enough to be observed, while the intensity of the $530 \mathrm{~nm}$ band increases slightly. The UV-edge absorption, on the other hand, is shifted towards higher wavelengths. As a consequence, the lilac spodumene turns to emerald green. Since these absorption bands decay under UV light exposure, the green color fades out quickly.

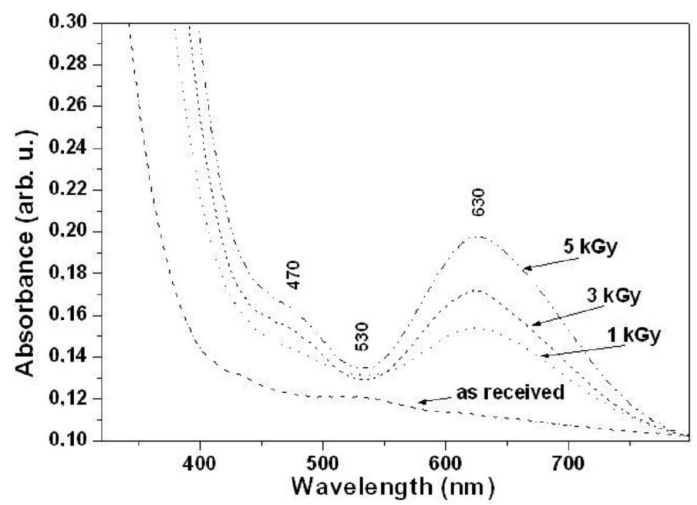

Fig. 3. Optical absorption spectra of the lilac spodumene subjected to additional gamma doses.

Isotani et al. [4] observed that the intensity of OA band at $630-640 \mathrm{~nm}$ increases as function of gamma dose, and that it saturates between 6 and $7 \mathrm{kGy}$. They have shown further that this band decays under annealing between 170 and $225^{\circ} \mathrm{C}$ and assigned it to a $\mathrm{Z}^{2+}\left[\mathrm{Mn}^{4+}\right]$ defect center. Fujii and Isotani [6] did not 
find $630 \mathrm{~nm}$ absorption band in a spodumene sample containing Fe/Mn ratio that satisfies the criterion used by Isotani et al. [4]. Thus we conclude that the $630 \mathrm{~nm}$ band cannot be related to Mn ions.

As shown by McKeever [10], the so-called A bands in the OA spectrum of irradiated quartz is due to aluminum. Nassau and Prescott [11] decomposed these bands into three Gaussian shaped components peaking at 355, 480, and $620 \mathrm{~nm}$. The EPR and dielectric relaxation measurements have shown that these bands are related to an $\left(\mathrm{Al}^{3+}\right)^{0}$-hole center, which is a substitutional $\mathrm{Al}^{3+}$ ion that has captured a hole. The study of TL emission spectra of undoped, Fe and Mn doped synthetic $\beta$-spodumene [3] has shown that the TL recombination centers for the TL peaks at $175-220^{\circ} \mathrm{C}$ are due to intrinsic defects. These peaks presented a similar behavior of peak II, which means that the latter is also probably due to intrinsic defects. Since the 360,470 , and $630 \mathrm{~nm}$ OA bands are thermally destroyed in the region of $175-230^{\circ} \mathrm{C}$, turning the radiation induced green color into lilac again, one can conclude that these absorption bands and the peak II are due to $\left(\mathrm{Al}^{3+}\right)^{0}$ center.

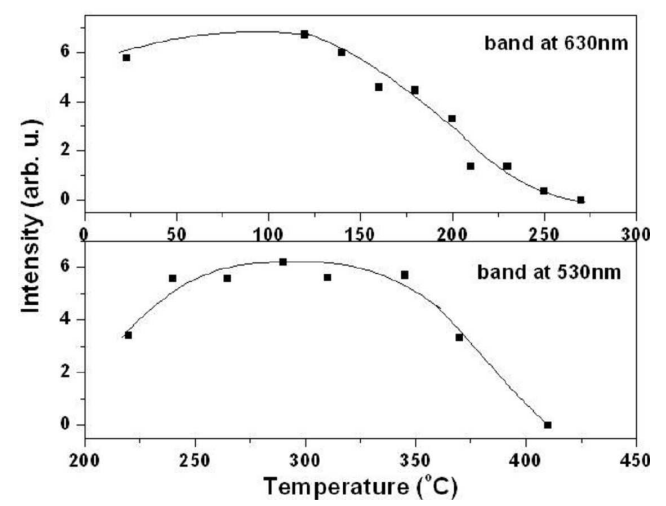

Fig. 4. Annealing behavior of principal optical absorption bands for lilac spodumene previously irradiated with 2 kGy gamma dose.

One interesting feature observed in the OA spectra refers to $530 \mathrm{~nm}$ band. Heating the sample at $400^{\circ} \mathrm{C}$, this band practically disappears and the crystal becomes colorless $[6,9]$. However, we found that on annealing between 250 and $300^{\circ} \mathrm{C}$ the $530 \mathrm{~nm}$ band intensity is enhanced (Fig. 4), and as a consequence the lilac color of spodumene is also enhanced. The $530 \mathrm{~nm}$ band is related to $\mathrm{Mn}^{3+}$ ions $[6,9]$.

Here, we propose that $\mathrm{Mn}^{4+}$ is found in natural lilac spodumene, substituting $\mathrm{Al}^{3+}$ ions. For charge compensation, $\mathrm{Mn}^{2+}$ ions substitutes for another $\mathrm{Al}^{3+}$ ions, neighbor to the $\mathrm{Mn}^{4+}$ ions. Heating the spodumene between 200 and $300^{\circ} \mathrm{C}$ liberates holes from $\mathrm{Mn}^{4+}$ ions, which become $\mathrm{Mn}^{3+}$, increasing therefore the intensity of TL peaks III, IV, and V and the $530 \mathrm{~nm}$ band. As a consequence, 
lilac is enhanced. Above $300^{\circ} \mathrm{C}$ further annealing release electrons from $\mathrm{Mn}^{3+}$, thus the $530 \mathrm{~nm}$ band decreases, decreasing the color of spodumene that becomes colorless around $400^{\circ} \mathrm{C}$.

\section{Conclusions}

The most important conclusion of this work is that a thermal treatment around $230-250^{\circ} \mathrm{C}$ can be applied to natural lilac spodumene gems used in jewelry to increase its pink color.

\section{References}

[1] J.R. Clark, D.E. Appleman, J.J. Papike, Mineral. Soc. Am. Spec. Pap. 2, 31 (1969).

[2] G. Walker, A. Eljaer, R. Sherlock, T.J. Glynn, M. Czaja, Z. Mazurak, J. Lumin. 72-74, 278 (1997).

[3] S.O. Souza, G.M. Ferraz, S. Watanabe, Nucl. Instrum. Methods Phys. Res. B 218, 259 (2004).

[4] S. Isotani, A.T. Fujii, R. Antonini, W.M. Pontuschka, S.R. Rabbani, W.W. Furtado, An. Acad. Bras. Cie. 63, 127 (1991).

[5] F. Holuj, Can. J. Phys. 46, 287 (1968).

[6] A.T. Fujii, S. Isotani, An. Acad. Bras. Cie. 60, 127 (1988).

[7] M. Salis, Nuovo Cimento D 17, 33 (1995).

[8] P. Brovetto, V. Maxia, M. Salis, G. Spano, M. Lucco-Borlera, D. Mazza, Nuovo Cimento D 15, 1017 (1993).

[9] A.S. Ito, S. Isotani, Rad. Eff. Def. Solids 116, 307 (1991).

[10] S.W.S. McKeever, Thermoluminescence of Solids, Cambridge University, London 1985.

[11] K. Nassau, B.E. Prescott, Physica Status Solidi A 29, 659 (1975). 